\title{
Evaluation of Nested PCR in Blood, Urine and Stool in Detection of Typhoid Fever by Sequences in the VI Region of the Flagellin Gene
}

\author{
Aalaa Abouelnour ${ }^{1 *}$, Maysaa EI Sayed Zaki ${ }^{1}$, Sherif M. H. Elkannishy ${ }^{2,3^{*}}$ \\ ${ }^{1}$ Department of Clinical Pathology, Faculty of Medicine, Mansoura-35516, Egypt \\ ${ }^{2}$ Department of Toxicology, Mansoura Hospital, Mansoura University, \\ Mansoura-35516, Egypt \\ ${ }^{3}$ Department of Pharmacology and Toxicology, Faculty of Pharmacy, University of Tabuk, \\ Tabuk, 71491, Saudi Arabia \\ *Corresponding author
}

\section{A B S T R A C T}

\section{Keywords}

Typhoid fever nested Pcr -flagellin gene

Article Info

Accepted:

15December 2019

Available Online:

20 January 2020
Typhoid fever remain a leading cause of morbidity, mortality and economic loss regardless of age or gender in developing countries. A sensitive and specific test is urgently needed for the accuracy of the diagnosis. The clinical pictures is commonly misleading with other ferial diseases and diagnosis depends mainly on the laboratory. By using molecular method especially nested PCR it provides the highest sensitivity and specificity. To evaluate the sensitivity and specificity nested polymerase chain reaction (PCR) specific for Salmonella enterica serovar Typhi was used for the detection of the pathogen in blood, urine, and stool samples. This was a prospective study which involved from 81patients with clinical suspicion of typhoid fever. In addition to 20 patients with febrile condition of cause other than tyhoid. For each patient blood culture and widal test was done as in the routine lab processes of febrile condition. Out of 81 suspected cases of typhoid fever, nested PCR was able to detect gene sequences specific for $S$. typhi in 76 cases in blood and 56 cases in urine specimens each. and 39 cases in stool specimens However, $S$. typhi was isolated from only 32 cases in blood culture None of the febrile controls tested positive in blood culture, or PCR.

\section{Introduction}

Typhoid fever is a critical health problem in low and middle income countries. It is hard to evaluate the actual burden of typhoid fever in the world as the clinical presentation may be misleading with other febrile infections (1). According to date reported by WHO in 2014 approximately 21 million cases and 222,000 typhoid-related deaths occur annually worldwide (2). Typhoid fever is caused by Salmonella enteric serovar Typhi and is 
transmitted through the fecal-oral route by the consumption of contaminated water and food (3). The presence of a convalescent patient or a carrier actively passing the pathogen increases risk for diseases transmission. In endemic areas a recent contact with a patient or carrier is also a major risk factor. There is other contributing factors include low socioeconomic, poor hygienic conditions and water supplies $(4,5)$. About $3 \%$ become carriers and go on to excrete the organism, mostly lifelong. The patient may become carrier even after an asymptomatic infection (6).

An ideal diagnostic tool for identification of typhoid patients and carrier should be sensitive, specific as well as rapid (7).The classical and commonly used is serological method such as Widal test which gives inaccurate result especially with single titers, additionally the serious serious drawback of false positives and false false negative(8).

Confirmation of typhoid fever requires identification of $S$. typhi in clinical specimens by culture. unfortunately, blood culture which is is mostly used can detect only 45 to $70 \%$ of patients as it, depends on the amount of blood sample, the bacterial load, and sensitivity of culture medium $(9,10)$.

Along with the insufficiency of date recording the sensitivity and specificity specificity of laboratory test that mostly used in developing countries which Lead to undiagnosed of many cases or over estimation of the diseases and giving unnecessary treatment (11).

Consequently the molecular methods are considered a advisable for pathogen detection from body fluids and excretions of infected human due to highly sensitive and specific over Widal and blood culture methods. Molecular methods, in particular the polymerase chain reaction (PCR) based assays have been developed over the last few decades to overcome these disadvantage (12).

Occasionally, when the bacterial load is less than $5 \mathrm{CFU} / \mathrm{mL}$ in the blood of patients, it would be obstacle to be detected by conventional PCR however, this problem can be reduce by using nested PCR as it declare to be more sensitive and specific compared with the conventional PCR $(13,14)$.

In this study, we assessed the sensitivity of the nested PCR on blood samples and investigated whether the method can be used for the detection of $S$. typhi DNA in urine and stool sample.

\section{Materials and Methods}

This was a prospective study conducted from November 2016 to October 2017. All subjects were children who were younger than 18 years, had been admitted to Mansoura University Children Hospital with symptoms clinically similar to typhoid fever.

Blood samples for culture and PCR, and serum samples for serologic analysis were collected from all patients. Urine samples and stool samples were also collected.

For blood culture Five milliliters of blood was placed in $15 \mathrm{~mL}$ of Ox bile broth (Merck, Darmstadt, Germany) and incubated for 24 hours at $37^{\circ} \mathrm{C}$. One milliliter of this culture was then subculture on Salmonella Shigella (SS) agar (Oxoid, Basingstoke, United Kingdom), 24 hours incubation at $37^{\circ} \mathrm{C}$, and any growth was examined by Gram stain and biochemical testing with the triple sugar iron test, sulfide indole motility, methyl red Voges' Proskauer reactivity, citrate consumption, urease and decarboxylase activity, and carbohydrate fermentation of glucose, lactose, mannitol, sucrose, and and arabinose (15). The Widal test was done by the slide agglutination 
test is used as a screening test for the presence of anti TO and anti TH antibodies in the patient's serum (Murex Biotech Ltd., Dartford, United Kingdom) was performed and interpreted according to routine laboratory procedures (16).

DNA from blood samples was extracted by the procedure described by Haque et al.,

About $500 \mu \mathrm{L}$ to $1 \mathrm{~mL}$ of blood containing 20 $\mathrm{mM}$ Potassium EDTA as anticoagulant was centrifuged at 10,000 rpm for $5 \mathrm{~min}$. One $\mathrm{mL}$ of lysis buffer $(0.2 \%$ Triton X100 in TrisHCl $\mathrm{H}$ 8.0) was added to the pellet. Then the tube was centrifuged at 12,000 rpm for $6 \mathrm{~min}$ and the supernatant was discarded. The pellet was washed again with lysis buffer followed by distilled water. Finally the pellet was suspended in $20 \mu \mathrm{L}$ of distilled water. The tubes were sealed and subjected to lysis in boiling water for $20 \mathrm{~min}$, and brought back to room temperature before being used as a template for PCR $(17,18)$.

DNA was extracted from freshly collected, urine, and stool samples according to the the diatom-guanidiniumisothiocyanate (GuSCN) method described by Boom and others (19, 20).

\section{Molecular detection}

The nested PCR illustrated by Song and other scientists (21) with a modified forward primer for the first PCR as done by Frankel and others (22) to have better specificity is based on the amplification of unique sequences in the VI region of the flagellin gene.

The modified PCR amplifies a 458-basepair (bp) fragment corresponding to to nucleotides $1063-1530$ of the gene in the first reaction and a nested 343-bp 343-bp fragment corresponding to nucleotides 1072-1435 in the second reaction. The first PCR was done by the addition of 2 [1]L of extracted DNA to 25 [1]L of PCR mixture and amplification for 40 cycles $\left(1\right.$ minute at $94^{\circ} \mathrm{C}, 75$ seconds at $57^{\circ} \mathrm{C}$, and 3 minutes at $72^{\circ} \mathrm{C}$ ) in a thermocycler.

The PCR mixture consisted of standard PCR PCR buffer (100 mM Tris-HCl, pH 8.3, 1.5 $\mathrm{mM} \mathrm{MgCl} 2,50 \mathrm{mM} \mathrm{KCl}, 0.1 \%$ gelatin, 200[1]M 200-[1]M each of all four dNTPs, and 0.625 units of Taq DNA polymerase) in addition to 25pmol of primer ST1 (5[1]-ACT GCT AAA ACC ACT ACT-3[1]) and 25 pmol of primer ST2 (5[1]-ACT GCT AAA ACC ACT ACT-3[1]). The nested PCR was performed by putting of 2 [1]L of the PCR product to 20 [1]L of standard PCR buffer supplemented with 25 pmol of primer ST3 (5[1]-AGA TGG TAC TGG CGT TGC TC$3[1])$ and 25 pmol of primer ST4 (5[1]-TGG AGA CTT CGG TCG CGT AG-3[1]) and amplification for 40 cycles with the same temperature cycle program as for the first reaction. The PCR was performed without previous knowledge of the classification of the samples (23).

\section{Quality control}

Standard operational procedures were followed during processing of each sample. All the instruments used for sample processing were checked every morning for proper functioning.

E. coli ATCC 25922 was used as a reference strain.

\section{Data analysis and management}

Data were entered into an Excel spreadsheet analysis was operated in Excel and SPSS SPSS Statistics, Sensitivity, specificity, positive predictive value(PPV), and negative negative predictive value(NPV)were 
calculated as described by the TDR Diagnostics Evaluation.

Samples that were positive by either blood culture or PCR were considered composite reference standard positive: samples negative by both blood culture and PCR were composite reference standard negative(21).

\section{Results and Discussion}

The samples of 101 children were examined in this study in which 81 were suspected clinically of having typhoid fever

And twenty- children (19.8\%) were included as negative controls. They were selected of having other cause of ferial conditions other than typhoid fever.

The sex distribution in the studied group was(51.5\%) males and 49(48.5\%) females. Median age of the patient was 9.5 years and median duration of fever was 10.5 days

By taking the history of antibiotic use it was that $(71.6 \%)$ cases had history of antibiotic intake, $(28.3 \%)$ did not have any antibiotic.

Widal was positive was positive only in (35.8\%) of suspected cases of typhoid also it was positive in $(20 \%)$ in the negative control subject

Out of 81 suspected cases of typhoid fever, PCR was able to detect gene sequences specific for $S$. typhi in 75 cases in blood and 56 cases in urine specimens each. and 39 cases in stool specimens However, S. typhi was isolated from only 32 cases in blood culture.

None of the febrile controls tested positive in blood culture, or PCR.

By calculation the sensitivities of blood culture, Widal test and PCR on blood PCR on urine, PCR on feces. Widal test shows the least specificity (37.2\%) followed by blood culture $(39.5 \%)$ then PCR on stool sample was slightly higher $(51.5 \% \%)$ and PCR on urine sample (64.2\%) finally the pc $\mathrm{r}$ on blood shows (93\%)sensitivity Table (1).

The negative predictive value varies between the test with pcr on blood shows $100 \%$ value while on calculation of positive predictive value all the pcr performed on blood urine and stool as well as the blood culture shows $(100 \%)$ only the widal test shows $(87.8 \%)$

The sensitivity of the nested PCRs on blood (P $<0.001$ ) and urine (P 0.01) were significant higher, and the sensitivity of the nested PCR on feces $(\mathrm{P}>0.05)$ was similar to the sensitivity of blood culture.

Three patients with a clinical diagnosis of typhoid fever showed negative results in blood culture and the three PCRs on blood, urine, and stool. Table (2).

Typhoid fever is a pervasive health dilemma in many developing countries. The clinical presentations of the disease are non-specific and laboratory diagnosis is mandatory.

Culture grants a sure result of existing of typhoid fever. The bone marrow culture is the gold standard of typhoid diagnosis, but the blood culture is frequently taking as the reference standard in diagnosis of typhoid as the difficulty of taking the bone marrow and it is not accessible in every laboratory

In the studied group only (39.5\%) out of 81 clinically suspected typhoid patients shows growth in the blood culture and no growth was detected in the remaining 49patients. The low specificity of blood culture is may be related to the antibiotic effect as there is no restrictions for the antibiotic use in many of developing countries as Egypt in this study 59 (72.8\%) had broad spectrum antibiotic.(24). Another factor is the late consultation 7-10 
days after the onset of fever and the use of only of one sample not multiple samples as recommended. This lead to reduce number of typhoid bacilli in the blood to level which can't be detected. (25).

The utilization of a nested PCR especially by using a segment of the flagellin gene of $S$. typhi in whole blood samples showed positive results for all the patient with positive blood culture, in addition to 46 patients with no growth was detected in the blood culture with clinical manifestation of typhoid fever.

And there were three sample didn't give positive result with any of PCR or the blood culture in spite being diagnosed clinically as typhoid fever.

The results of positive nested PCR for blood samples from culture-negative typhoid patients is rational and goes with the previous studies which demonstrate that PCR, specially the nested PCRs, provide higher sensitivities than blood culture.(26).

Prakash and others who recorded a sensitivity of $29.8 \%$ for blood culture and $82.8 \%$ for the nested PCR, by using same nested PCR but a different DNA extraction method and in study done by Hague and others blood culture sensitivity was14.5\% and for the nested PCR was $88.2 \% .(27)$.

This extreme variations depend on the sample and the method used also the target gene play important role in evaluation the process.

In this study nested PCR result gives higher sensitivity this may be contributed to the use of $3 \mathrm{ml}$ of blood for DNA extraction. Also elimination of the inhibitors of PCR like $d$ by using only $4 \mathrm{ml}$ of 6 times diluted product of 1 st cycle as template for the nested round

Patients that excrete the bacteria in stool and /or urine are potential sources of spreading the disease. Rigid sanitary precautions should be done to prevent spread of infection. Also their early detection promote elimination of the disease.

As enormous pathogens may be found in the urine and stool of typhoid patients, the specificity DNA detection methods need more study, also the presence of viable pathogen. Our results demonstrate that the nested PCR is effective in delectation $S$. typhi DNA in urine or stool from patients with typhoid fever.

Table.1 Sensitivity specificity and predicative value (positive and negative) of PCR urine,stool, blood culture and Widal test using the PCR blood as gold standard

\begin{tabular}{|c|c|c|c|c|}
\hline Test & Sensitivity & Specificity & NPV & PPV \\
\hline Widal & $80 \%$ & $35.8 \%$ & $23.53 \%$ & $\mathbf{8 7 . 8 \%}$ \\
\hline $\begin{array}{c}\text { Blood } \\
\text { culture }\end{array}$ & $100 \%$ & $55.56 \%$ & $35.71 \%$ & $\mathbf{1 0 0 \%}$ \\
\hline PCR blood & $100 \%$ & $100 \%$ & $100 \%$ & $\mathbf{1 0 0 \%}$ \\
\hline PCR urine & $100 \%$ & $64.2 \%$ & $40.82 \%$ & $\mathbf{1 0 0 \%}$ \\
\hline PCR stool & $100 \%$ & $48.15 \%$ & $32.26 \%$ & $\mathbf{1 0 0 \%}$ \\
\hline
\end{tabular}

NPV;NegativePredicative Value

PPV; Positive Predicative Value 
Table.2 Correlation between result of blood culture PCR result and Widal test in clinically suspected typhoid in relation to duration of fever and duration of antibiotic

\begin{tabular}{|c|c|c|c|c|c|}
\hline $\begin{array}{c}\text { Patient } \\
\text { number } \\
\text { No(81) }\end{array}$ & $\begin{array}{c}\text { Blood } \\
\text { culture } \\
\text { No(32/81) }\end{array}$ & $\begin{array}{c}\text { PCR } \\
\text { NO(76/81) }\end{array}$ & $\begin{array}{c}\text { Widal test } \\
\text { NO(39/81) }\end{array}$ & $\begin{array}{c}\text { Duration of } \\
\text { antibiotic/DAYS }\end{array}$ & $\begin{array}{c}\text { Duration of } \\
\text { fever/DAYS }\end{array}$ \\
\hline 3 & $0 / 3$ & $0 / 3$ & $0 / 3$ & NOT USING & $\mathbf{2 - 3}$ \\
\hline 7 & $4 / 7$ & $7 / 7$ & & $10-15$ & $\mathbf{1 5 - 2 0}$ \\
\hline 10 & $0 / 10$ & $10 / 10$ & $6 / 10$ & $2-5$ & $\mathbf{5 - 1 0}$ \\
\hline 20 & $16 / 20$ & $20 / 20$ & $14 / 20$ & $15-20$ & $\mathbf{2 0 - 2 5}$ \\
\hline 18 & $12 / 22$ & $20 / 22$ & $9 / 22$ & $5-10$ & $\mathbf{1 0 - 1 5}$ \\
\hline 23 & $0 / 23$ & $19 / 23$ & $0 / 23$ & NOT & $\mathbf{5 - 1 0}$ \\
\hline
\end{tabular}

The sequences in the VI region of the flagellin gene was detected in both the urine and stool samples it was present $(69.1 \%)$ in urine sample and only in $(48.1 \%)$ of the stool samples. The PCR on stool samples may have been less beneficial due to the presences of inhibitors which present at higher concentrations in stool samples than in urine samples and the difficulty of removing these inhibitors (28).

Detection for typhoid from urine has advantage of easy collection and the sensitivity of the PCR was accepted. And it was more than the blood culture as patient showed positive results in urine PCR and no growth was detected in blood culture. Similar result was also reported in by M.Hatta and $e t$ al., in study done in Indonesia (29).

The most advantages of using Widal test rapid result however it is of limited value as it has low sensitivity and specificity. In this study it was positive only in $(35.8 \%)$ of typhoid cases and also gives false positive result in (20\%) of febrile nontyphoid controls. Past immunization or infection, cross reaction with other Salmonellae, anamnestic response are different cause of false positivity.

Besides that Widal test is not agood choices for early detection of the disease as the specific antibodies needs at least a week to reach detectable

More than that the use of single Widal test has got little diagnostic significance until the sensitivity and specificity of the test at different cut-off titers are known for a defined population, single tube widal test with TO and/or TH titers $\geq 1: 160$ was taken as cut-off value in many endemic regions as Egypt.(30).

Rising antibody titers has been routinely taken as a satisfactory diagnostic test, but it is not applicable and antibiotics use may affect the rise of the titer.

Blood culture is relative insensitive and timeconsuming, and the sensitivity and specificity of serologic analysis with the Widal test is too low to useful in diagnosis.

The sensitivity of bone marrow culture is reported to be higher but this invasive method is not always practicable. PCR is time saving and offers high sensitive and specific outcome for the diagnosis of typhoid fever. Also it provides the results in less time than conventional culture and along these lines, it should be implemented as a dependable tool to detect $S$. typhi for routine clinical cases.

On the other hand a nested PCR is relatively complicated to perform and not suitable test to 
be used in daily routine work especially in developing countries where typhoid fever is endemic also the cost will be a huge obstacle.

Besides that the presence of $S$. paratyphi in these endemic areas may have interferences and effect the specificity of the result. there is urgent need for improvement of diagnostic test of typhoid fever that is suitable and applicable in the endemic areas

\section{References}

Abida Raza, Yasra Sarwar, Aamir Ali, AmerJamil, AsmaHaque, Abdul Haque. Effect of biofilm formation on the excretion of Salmonella entericaserovar Typhi in feces. International Journal of Infectious Diseases 15, e747-e752 Elsevier BV, 2011.

Albert M. Vollaard, Soegianto Ali, Suwandhi Widjaja, Henri A.G.H. van Asten, Leo G. Visser, Charles Surjadi, Jaap T. van Dissel. Identification of typhoid fever and paratyphoid fever cases at presentation in outpatient clinics in Jakarta Indonesia. Transactions of the Royal Society of Tropical Medicine and Hygiene 99, 440-450 Oxford University Press (OUP), 2005.

Annette Anderson, Klaus Pietsch, Renate Zucker, AnjaMayr, Elke Müller-Hohe, Ute Messelhäusser, Andreas Sing, Ulrich Busch, Ingrid Huber. Validation of a Duplex Real-Time PCR for the Detection of Salmonella spp. in Different Food Products.Food Analytical Methods 4, 259-267 Springer Science and Business Media LLC, 2010.

Baker, S., Y. Sarwar, H. Aziz, A. Haque, A. Ali, G. Dougan, J. Wain, A. Haque. Detection of Vi-Negative Salmonella entericaSerovarTyphi in the Peripheral Blood of Patients with Typhoid Fever in the Faisalabad Region of Pakistan.Journal of Clinical Microbiology 43, 4418-4425 American Society for Microbiology, 2005.
Charlotta Löfström, Michael Krause, Mathilde H Josefsen, Flemming Hansen, Jeffrey Hoorfar. Validation of a same-day realtime PCR method for screening of meat and carcass swabs for Salmonella. BMC Microbiology 9, 85 Springer Science and Business Media LLC, 2009.

Hapuarachchi, C. T., Katie J. M. Jeffery, I. C. J. W. Bowler. Stool PCR may not be a substitute for enrichment culture for the detection of salmonella. Journal of Medical Microbiology 68, 395-397 Microbiology Society, 2019.

Haque, A., N Ahmed, APeerzada, A Raza, S Bashir, G Abbas. Utility of PCR in diagnosis of problematic cases of typhoid..Jpn J Infect Dis 54, 237-9 (2001).

Henry Wilde. Enteric fever due to Salmonella typhi and paratyphi A. Vaccine 25, 5246-5247 Elsevier BV, 2007.

House, D., J. Wain, V. A. Ho, T. S. Diep, N. T. Chinh, P. V. Bay, H. Vinh, M. Duc, C. M. Parry, G. Dougan, N. J. White, T. T. Hien, J. J. Farrar. Serology of Typhoid Fever in an Area of Endemicity and Its Relevance to Diagnosis.Journal of Clinical Microbiology 39, 1002-1007 American Society for Microbiology, 2001.

House, D., N. T. Chinh, T. S. Diep, C. M. Parry, J. Wain, G. Dougan, N. J. White, T. T. Hien, J. J. Farrar. Use of Paired Serum Samples for Serodiagnosis of Typhoid Fever.Journal of Clinical Microbiology 43, 4889-4890 American Society for Microbiology, 2005.

James Galen, Marcela Pasetti, Marcelo Sztein. Attenuated Strains of Salmonella enterica Serovars Typhi and Paratyphi as Live Oral Vaccines Against Enteric Fever. 497-505 In New Generation Vaccines Fourth Edition. CRC Press, 2009.

John A. Crump, Eric D. Mintz. Global Trends in Typhoid and Paratyphoid Fever.Clinical Infectious Diseases 50, 241-246 Oxford University Press (OUP), 2010. 
John Wain, To Song Diep, Phan Van Be Bay, Amanda L. Walsh, Ha Vinh, Nguyen M. Duong, Vo Anh Ho, Tran T. Hien, Jeremy Farrar, Nicholas J. White, Christopher M. Parry, Nicholas P. J. Day. Specimens and culture media for the laboratory diagnosis of typhoid fever. The Journal of Infection in Developing Countries 2 Journal of Infection in Developing Countries, 2008.

Lawrence Proano.Salmonella typhi (Typhoid Fever) Attack. 735-737 InCiottones Disaster Medicine. Elsevier, 2016.

Levy, H., S. Diallo, S. M. Tennant, S. Livio, S. O. Sow, M. Tapia, P. I. Fields, M. Mikoleit, B. Tamboura, K. L. Kotloff, R. Lagos, J. P. Nataro, J. E. Galen, M. M. Levine. PCR Method To Identify Salmonella enterica Serovars Typhi Paratyphi A, and Paratyphi B among Salmonella Isolates from the Blood of Patients with Clinical Enteric Fever. Journal of Clinical Microbiology 46, 1861-1866 American Society for Microbiology, 2008.

Mashouf, RY, MY Alikhani, S Azadi. Detection of Salmonella species isolated from clinical specimens by serotyping and polymerase chain reaction..Saudi Med J 28, 1751-3 2007.

Mochammad Hatta, Marga G A Goris, JairoGooskens, Henk L Smits, EvyHeerkens. Simple dipstick assay for the detection of Salmonella typhispecific $\operatorname{IgM}$ antibodies and the evolution of the immune response in patients with typhoid fever..The American Journal of Tropical Medicine and Hygiene 66, 416-421 American Society of Tropical Medicine and Hygiene, 2002.

N George, P Sethi, N Nischal, A Kumar, G Siripurapu, N Wig, S Vyas. A Catastrophic Presentation of Enteric Fever with Secondary HemophagocyticLymphohistiocytosis..J Assoc Physicians India 66, 11-12 2018.

Nandakumar, K. S., V. Palanivel, VR.Muthukkaruppan. Diagnosis of typhoid fever: detection of Salmonella typhiporins-specific antibodies by inhibition ELISA. Clinical \& Experimental Immunology 94, 317-321 Wiley, 2008.

Oliveira, S.D., C.R. Rodenbusch, M.C. Cé, S.L.S. Rocha, C.W. Canal. Evaluation of selective and non-selective enrichment PCR procedures for Salmonella detection. Letters in Applied Microbiology 36, 217-221 Wiley, 2003.LinkEdit

Pasupathi Aarthi, Rajagopal Harini, Murali Sowmiya, Jambulingam Malathi, K. Lily Therese, Hajib N. Madhavan. Identification of bacteria in culture negative and polymerase chain reaction (PCR) positive intraocular specimen from patients with infectious endopthalmitis.Journal of Microbiological Methods 85, 47-52 Elsevier BV, 2011.

Peter J. Hart, Colette M. O'Shaughnessy, Matthew K. Siggins, SaeedaBobat, Robert A. Kingsley, David A. Goulding, John A. Crump, Hugh Reyburn, Francesca Micoli, Gordon Dougan, Adam F. Cunningham, Calman A. MacLennan. Differential Killing of Salmonella entericaSerovarTyphi by Antibodies Targeting $\mathrm{Vi}$ and Lipopolysaccharide O:9 Antigen. PLOS ONE 11, e0145945 Public Library of Science (PLoS), 2016.

Prakash, O. P. Mishra, A. K. Singh, A. K. Gulati, G. Nath. Evaluation of Nested PCR in Diagnosis of Typhoid Fever. Journal of Clinical Microbiology 43, 431-432 American Society for Microbiology, 2005.

Shabir Banoo, David Bell, Patrick Bossuyt, Alan Herring, David Mabey, Freddie Poole, Peter G Smith, N. Sriram, Chansuda Wongsrichanalai, Ralf Linke, Rick OBrien, Mark Perkins, Jane Cunningham, Precious Matsoso, Carl Michael Nathanson, PieroOlliaro, Rosanna W. Peeling, Andy Ramsay. Evaluation of diagnostic tests for 
infectious diseases: general principles. Nature Reviews Microbiology 5, S21S31 Springer Science and Business Media LLC, 2007.

Sharma, D., J Khan, S Agarwal. Salmonella typhi as cause of neonatal sepsis: case report and literature review..J Matern Fetal Neonatal Med, 1-4 (2019).

Solai Ramatchandirane Prabagaran, Vellingiri Kalaiselvi, Naganathan Chandramouleeswaran, Krishnan Nair Geetha Deepthi, Kootallur Narayanan Brahmadathan, Mariappa Mani. Molecular diagnosis of Salmonella typhi and its virulence in suspected typhoid blood samples through nested multiplex PCR. Journal of Microbiological Methods 139, 150-154 Elsevier BV, 2017.

Sven Maurischat, Beatrice Baumann, Annett Martin, BurkhardMalorny. Rapid detection and specific differentiation of Salmonella enterica subsp. Enterica Enteritidis Typhimurium and its monophasic variant 4,[5],12:i:- by realtime multiplex PCR. International
Journal of Food Microbiology 193, 8-14 Elsevier BV, 2015.

Svetlana Egorova, Lydia Kaftyreva, Patrick A.D. Grimont, François-Xavier Weill.Prevalence and Characterization of Extended-Spectrum CephalosporinResistant Nontyphoidal Salmonella Isolates in Adults in Saint Petersburg Russia (20022005).Microbial Drug Resistance 13, 102-107 Mary Ann LiebertInc, 2007.

Wolffs, P. F. G, K. Glencross, R. Thibaudeau, M. W. Griffiths. Direct Quantitation and Detection of Salmonellae in Biological Samples without Enrichment Using Two-Step Filtration and Real-Time PCR. Applied and Environmental Microbiology 72, 3896-3900 American Society for Microbiology, 2006.

Zainab Rahmat, Aamir Ali, YasraSarwar, Muhammad Salman, Abdul Haque. Purification and antigenic detection of O-specific polysaccharides of Salmonella entericaserovar Paratyphi A isolate from Pakistan: an emerging threat. SpringerPlus 5 Springer Nature, 2016.

\section{How to cite this article:}

Aalaa Abouelnour, Maysaa El Sayed Zaki, Sherif M. H. Elkannishy. 2020. Evaluation of Nested PCR in Blood, Urine and Stool in Detection of Typhoid Fever by Sequences in the VI Region of the Flagellin Gene. Int.J.Curr.Microbiol.App.Sci. 9(01): 556-564.

doi: https://doi.org/10.20546/ijcmas.2020.901.061 